\title{
Analysis on Influencing Factors of Crowdfunding Project Financing
}

\author{
Ying Xu \\ Nanjing University of Science \&Technology, Nanjing, 210094, China \\ 741217968@qq.com
}

Keywords: Crowdfunding, entrepreneurship, internet finance, influencing factors

\begin{abstract}
With the gradual development of "Internet +", online financing has gradually become a means of financing for SMEs. In March 2016, Premier Li Keqiang proposed in the "Government Work Report" to "build a platform for innovation, crowdsourcing, and crowdfunding, and build a system of innovative mechanisms for large and medium-sized enterprises, universities, research institutions, and multi-party synergies." As an emerging Internet financing model, crowdfunding provides a new solution to the dilemma of financing difficulties for SMEs, and plays an important role in promoting the process of "mass entrepreneurship and innovation”. This paper mainly studies and analyzes the development of crowdfunding in China and its factors affecting the success or failure of crowdfunding.
\end{abstract}

\section{Introduction}

As a new type of "Internet + financing", crowdfunding is conducive to promoting "mass entrepreneurship and innovation”, and thus promotes the transformation and upgrading of China's economy. Promoting "double innovation" can reform the irrational mechanism and improve the overall efficiency of economic operations. Its operation mode is to integrate decentralized and popular resources and integrate resources at a low cost.

In July 2011, the "name time” was launched, and then crowdfunding websites such as crowdfunding network, dream catching net, motorcycle network, and venture capital network gradually developed. With the gradual promotion of the "Internet Plus" policy, "Taobao Crowdfunding" was officially established in 2013. In July 2014, Jingdong Crowdfunding was officially developed. The following year, the Suning Crowdfunding Platform was successfully launched, and the crowdfunding pattern was clear. . According to statistics, in 2017, there were a total of 76,670 crowdfunding projects in China's crowdfunding platform, of which 69,637 successful crowdfunding projects accounted for 90.83\%; in 2017, the amount of crowdfunding financing for successful projects was about 26 billion. Yuan, a year-on-year increase of $19.58 \%$.

\section{The concept of crowdfunding}

Crowdfunding was first proposed by American scholar Michael J. Sullivan in August 2006. Schwienbacher (2010) and others believe that crowdfunding is decentralized, a model of open demand, and its model breaks the barriers of traditional financial intermediation. Ordanini (2010) and 
others believe that crowdfunding is a financing model that supports public resources to support projects. The relevant entities of crowdfunding generally include project sponsors, investors, crowdfunding platforms and government supervision and management departments. Crowdfunding initiated by different platforms and groups often leads to different factors influencing success.

\section{Empirical analysis of the factors affecting crowdfunding project financing}

\subsection{Sample data selection}

In 2014, Jingdong Crowdfunding was established and became the largest crowdfunding platform in China. In the year after its establishment, the total financing of the Jingdong crowdfunding platform exceeded 1 billion yuan. In the first half of 2017, the number of successful projects on the platform was 1,867, and the total amount of funds raised was 92,314,400 yuan. This paper chooses to collect the completed project data on the Jingdong crowdfunding platform, and uses the data of the projects initiated and completed by Jingdong Crowdfunding from January 2018 to March 2018, a total of 249 items. Among them, 117 data were selected for technology-based crowdfunding projects, 92 for design-based crowdfunding projects, 26 for cultural crowdfunding projects, and 14 for other crowdfunding projects.

\subsection{Research factors on the influencing factors of crowdfunding projects}

This article assumes that:

Hl: The number of crowdfunding project support has a positive impact on the percentage of total fundraising in the target amount;

H2: The frequency of progress of crowdfunding project progress has a positive correlation with the percentage of total fundraising in the target amount;

H3: The number of people with minimum investment in crowdfunding projects has a negative impact on the percentage of total fundraising in the target amount;

H4: The minimum investment amount of the crowdfunding project has a negative impact on the percentage of total fundraising in the target amount;

H5: The target amount of the crowdfunding project has a negative impact on the percentage of total fundraising in the target amount.

\subsection{Variable description and statistical description of the data}

In this paper, the percentage of the total fundraising amount is taken as the explanatory variable. In terms of explanatory variables, there are five variables, namely the project target financing amount (Goal), the project support number (Backers), and the minimum investment amount (Ratio), project update frequency (Updates), project minimum investment amount (Price).

A statistical analysis of the overall sample was taken for the collected sample data. The detailed statistical results are shown in Table 1.

From Table 1, the following conclusions can be drawn:

(1) Judging from the statistical description of the overall sample data, the standard deviation of the total financing amount of the sample data is large, reaching 21,146,465.42 yuan, and the amount difference between the maximum and minimum values is also relatively large, which indicates that in all the public In the successful project, there is a difference in project quality.

(2) The number of supporters represents the level of attention of the crowdfunding project. The number of supporters for the project is 936. It shows that crowdfunding projects have attracted the attention of a considerable number of participants in the process of crowdfunding. 
(3) From the overall sample data, the average investment amount of the crowdfunding project is 520 yuan, which indicates that the threshold for participation in crowdfunding is low, and the expected return value of investors is not high, reflecting the public trend of crowdfunding.

Table 1 Overall sample statistical description

\begin{tabular}{|c|c|c|c|c|c|c|}
\hline Category & $\begin{array}{c}\text { Financing } \\
\text { amount } \\
\text { (yuan) }\end{array}$ & $\begin{array}{c}\text { Financing } \\
\text { target (yuan) }\end{array}$ & $\begin{array}{c}\text { Support } \\
\text { number } \\
\text { (person) }\end{array}$ & $\begin{array}{c}\text { Update } \\
\text { frequency } \\
\text { (times) }\end{array}$ & $\begin{array}{c}\text { Minimum } \\
\text { investment } \\
\text { amount } \\
\text { (yuan) }\end{array}$ & $\begin{array}{c}\text { Minimum } \\
\text { investment } \\
\text { amount } \\
\text { (person) }\end{array}$ \\
\hline Max & 30110055 & 1000000 & 13904 & 34 & 28000 & 9256 \\
\hline Min & 10589 & 10000 & 3 & 0 & 0 & 0 \\
\hline $\begin{array}{c}\text { Average } \\
\text { value }\end{array}$ & 598844.1566 & 97590.36145 & 936.562249 & 6.987951807 & 520.5863454 & 363.060241 \\
\hline $\begin{array}{c}\text { Standard } \\
\text { deviation }\end{array}$ & 2114656.42 & 92930.65002 & 1726.781646 & 7.055358252 & 1899.572643 & 939.2302101 \\
\hline
\end{tabular}

\subsection{Multiple linear regression and results analysis}

(1) Research model

In this paper, the multiple linear regression model is used to regress the data, and the correlation and significance between each explanatory variable and the explained variable are obtained. This paper sets the following multiple linear regression model:

$$
\text { Resultln }=\beta_{0}+\beta_{1} \text { Goalln }+\beta_{2} \text { Backersln }+\beta_{3} \text { Updatesln }+\beta_{4} \text { Priceln }+\beta_{5} \text { Ratioln }
$$

(2) Correlation analysis

In this study, the data was sorted out, and the impact of classification was removed. Correlation analysis was performed on the 249 raw data collected using Eviews 8 software. The correlation between specific variables and their correlation coefficients are shown in Table 2.

Table 2 Correlation coefficient matrix

\begin{tabular}{|c|c|c|c|c|c|}
\hline Correlation & Goal & Backers & Updates & Price & Ratio \\
\hline Goal & 1.000000 & & & & \\
\hline Backers & 0.316640 & 1.000000 & & & \\
\hline Updates & 0.049032 & 0.179115 & 1.000000 & & \\
\hline Price & 0.029694 & -0.102634 & 0.005286 & 1.000000 & \\
\hline Ratio & -0.034979 & 0.664562 & 0.161556 & -0.074416 & 1.000000 \\
\hline
\end{tabular}

According to the analysis of the pearson correlation coefficient, the analysis results of the above table show that the correlation coefficient between each explanatory variable is below 0.4 , so it indicates that the variables are weakly correlated or uncorrelated, so it is reasonable to use these data.

Linear regression analysis: 
Table 3 Regression results for each model

\begin{tabular}{cccccc}
\hline & Model 1 & Model 2 & Model 3 & Model 4 & Model 5 \\
\hline C & -0.999435 & $10.85548^{* * *}$ & -0.638309 & -7.758934 & $10.19584^{*}$ \\
& $(1.060308)$ & $(0.328350)$ & $(2.513024)$ & $(5.362274)$ & $(1.094636)$ \\
Goalln & $-0.207433^{* *}$ & & -0.199484 & 0.676346 & - \\
& $(0.097916)$ & - & $(0.223394)$ & $(0.563946)$ & \\
Backersln & $0.599200^{* * *}$ & $0.139527 * * *$ & $0.443887 * * *$ & $0.643869 * * *$ & -0.033981 \\
& $(0.066090)$ & $(0.047833)$ & $(0.127479)$ & $(0.347378)$ & $(0.180226)$ \\
Updatesln & -0.013943 & -0.016449 & 0.061520 & $0.405954 *$ & $0.166701^{* * *}$ \\
& $(0.061729)$ & $(0.055333)$ & $(0.105951)$ & $(0.219336)$ & $(0.098906)$ \\
Priceln & $0.241265^{* * *}$ & $0.060928^{*}$ & $0.249058 * * *$ & -0.033023 & $0.238916^{* * *}$ \\
& $(0.041923)$ & $(0.031712)$ & $(0.085045)$ & $(0.117041)$ & $(0.144448)$ \\
Ratioln & $-0.079422^{*}$ & $-0.072432^{* *}$ & -0.002236 & $-0.617042 *(0$. & 0.089438 \\
& $(0.047634)$ & $(0.035742)$ & $(0.084833)$ & $348294)$ & $(0.190336)$ \\
Observations & 221 & 108 & 79 & 22 & 12 \\
$\mathrm{R}^{2}$ & 0.401489 & 0.426269 & 0.347921 & 0.683492 & 0.467907 \\
\hline
\end{tabular}

Note: ***, **, * indicate that the significance level is $1 \%, 5 \%, 10 \%$, respectively.

There is a positive correlation between the number of crowdfunding project supporters and the total fundraising percentage as a percentage of the target amount. In models $1,2,3$, and 4 , a $1 \%$ significance level test was passed, assuming $\mathrm{H} 1$ was verified.

The frequency of update of crowdfunding projects has passed the $10 \%$ and $1 \%$ significance level tests in models 4 and 5 respectively. The coefficients are positive in models 3,4 and 5 . The progress of project update frequency and total crowdfunding fund are the targets. There is a certain positive correlation between the percentage of the amount, and thus $\mathrm{H} 2$ is assumed to be verified.

The coefficient of the minimum investment amount is negative. In the models 1,2 , and 4 , the significance level tests of $10 \%, 5 \%$, and $10 \%$ are respectively passed. This indicates that the more the minimum investment amount, the more the investor can indicate The lack of confidence or interest in the project can lead to a decline in the percentage of funding, which is assumed to be verified by H3.

The minimum investment amount of the crowdfunding project is positive in the models $1,2,3$, and 5 , and the models 1,3 , and 5 have passed the $1 \%$ saliency water test, and the model 2 passed the 10 The significance level of \%, the minimum investment amount and the total amount of crowdfunding funds accounted for a positive percentage of the target amount, assuming H4 does not hold.

It can be seen from Model 1 that the coefficient of financing target is negative and passed the 5\% significance level test, indicating that the fund demand is smaller, the crowdfunding project is easier to crowdfund, the negative correlation effect, and the overall test conclusion. Consistent, assume that $\mathrm{H} 5$ is verified.

\section{Suggestions and conclusions on crowdfunding project financing}

Crowdfunding based on the call of the times is an inevitable outcome of the development of Internet finance. From the perspective of the project sponsor, the project sponsor should set the appropriate target financing amount, collect rich project information, and improve the financing plan. Actively interact with investors and learn from the experience and opinions to make the project run more successfully. The sponsor promotes the project and raises the public awareness of the crowdfunding project. Government regulatory agencies should regulate crowdfunding industry 
regulations, conduct appropriate guidance and supervision, strengthen credit mechanisms, create a credit transparency system for the industry, and raise public awareness of crowdfunding. The development of the crowdfunding model in China still faces enormous opportunities and development. All departments should strive to promote the efficient and orderly development of China's crowdfunding market, so that under the "double innovation" environment, the "Internet +" industry can develop healthily and steadily, and the whole society can develop more harmoniously and healthily.

\section{References}

[1] Lam6ert T'Schwienbacher A. Crowdfunding:An Industrial Organization Perspective[J].2010.

[2] Shibo Xu,Lin Zhang,Wei Chen. Analysis of crowdfunding development under the environment of innovation and entrepreneurship [J].Global Technology Economics Outlook, 2017(2):32.

[3] Jiayu Fan. Research on crowdfunding business model [J]. Corporate Economy, 2013(8): 72-75.

[4] Bin Tang. Research on the factors influencing the success of crowdfunding in China [D]. Zhejiang University of Finance and Economics, 2016.

[5] Finance_01. Annual Report of Crowdfunding Service Industry [M]. Oriental Publishing House, 2017.

[6] Yuxi Chen, Ningwei Ni, Xiaoju Gou. A study on the success of crowdfunding projects in an innovative entrepreneurial environment [J]. Shanghai Economic Research, 2015 (11): 12-19. 